\title{
DESIGN AND DEVELOPMENT OF HIGH LOAD BRINELL HARDNESS STANDARD MACHINE AT UME
}

\author{
C. Kuzu${ }^{1}$, E. Pelit ${ }^{2}$ \\ ${ }^{1}$ UME, Kocaeli, Turkey, cihan.kuzu@ tubitak.gov.tr \\ ${ }^{2}$ UME, Kocaeli, Turkey, ercan.pelit@tubitak.gov.tr
}

\begin{abstract}
:
After successful implementation of two hardness standardizing machines at TSE (Turkish Standards Institution) in Rockwell and Brinell-Vickers hardness scales separately and deciding to combine them in one machine with a newer design and install it in Hardness Laboratory of UME (National Metrology Institute of Republic of Turkey) it was planned to design and develop a deadweight type Brinell Hardness standard machine at UME for high load scales within the scope of an internally funded project. In this paper the design of High Load Brinell Hardness Standard Machine with dead weight force application system realized by UME Hardness Laboratory is explained.
\end{abstract}

Keywords: Hardness, Brinell, Hardness Standard Machine

\section{INTRODUCTION}

With the demand of the Turkish Industry and in turn accredited calibration and testing laboratories, and after successful implementation of two hardness standardizing machines at TSE in Rockwell and Brinell-Vickers hardness scales separately, a high load Brinell hardness standard machine had been decided for first time to be designed and established at UME to provide traceability in the field of Brinell hardness measurements covering the range $187.5 \mathrm{kgf}$ $-3000 \mathrm{kgf}$. In this new design the force application system was considered to comprise mass stacks realizing force under the gravitational acceleration and a frame to transfer the realized force to the tip of the indenter, a very well known deadweight force application principle. The frame was supposed to generate the $187.5 \mathrm{kgf}$, which corresponds to the HBW 2.5/187.5 scale. There are 12 mass stacks to be added to the frame for realization of the other Brinell scales up to $3000 \mathrm{kgf}$.

An indentation measurement system will be needed for diameter length measurement for Brinell hardness. The indentation measurement system is not in the scope of this project, the system present in Hardness Laboratory will be used. As a future planning a new indentation measurement system with a better performance is under development.

The testing cycle is managed by making use of a load cell (force transducer) to which the whole force application system; the frame and the mass stacks as a whole, is mounted. The force application time and dwell duration are sensed by measuring the force on the load cell instantaneously during load application and calculating the change in force values with respect to the nominal (initial/reference) values belonging to the scale, then force - time relationship is plotted.

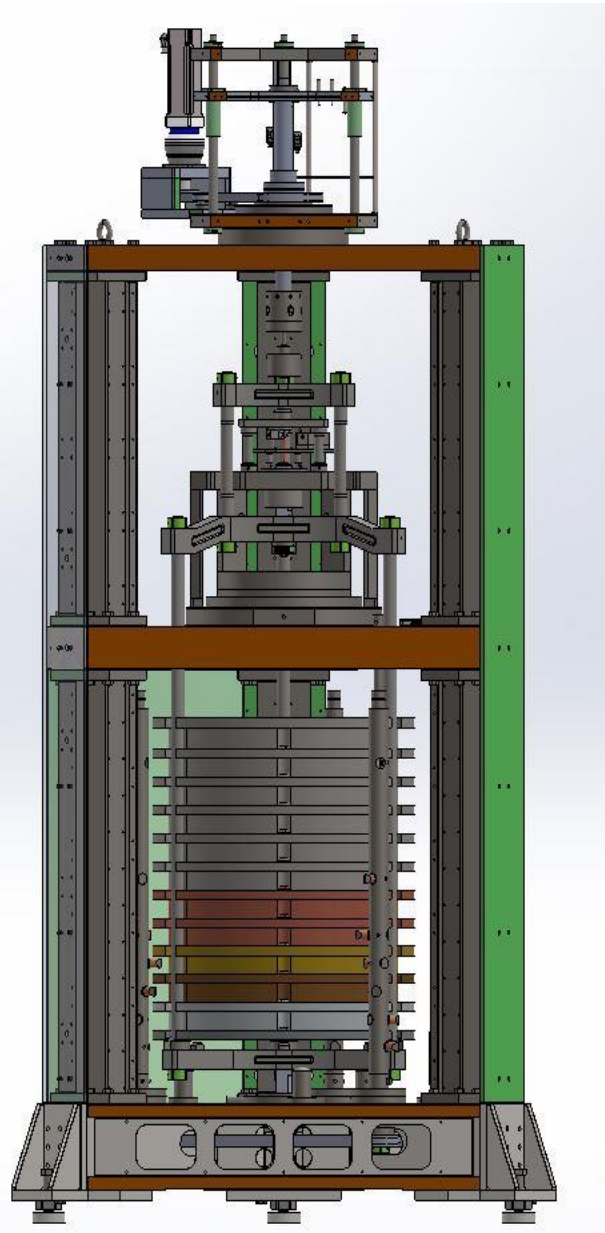

Figure 1: CAD of the High Load Brinell hardness standard machine 
The indenter approach, force application and removal speeds will be adjusted by calibrating the main servomotor (M1) which will be used for realization of the measurement cycle and force application rate is measured via the change in the load cell value in time. There is a second servo motor on the bottom side of the machine used to make automatic selection of the masses (scales) and with this design the machine will be completely automatic in terms of every step to realize the measurement cycle in Brinell scales indicated in the table 1. The $\mathrm{CAD}$ of the machine is given in figure 1 and drawing in figure 2.
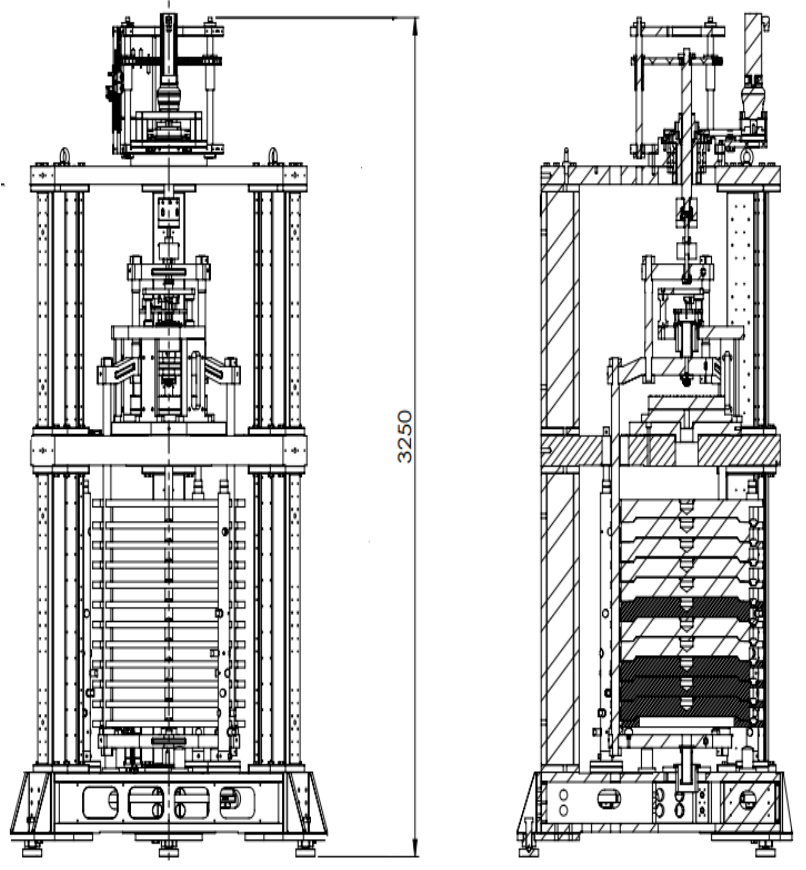

Figure 2: High Load Brinell hardness standard machine

\section{THEORY AND SCOPE}

The theory of Brinell Hardness measurement, as a well-known method, comprises realisation of indentation and measurement of the diameter of the indentation to be used for calculation of the Brinell Hardness number by making use of the empirical equation eqn. 1. This method is completely used to measure mechanical property of material in line with the hardness definition, that is, the resistance which a material shows against deformation. In this paper the design of the machine used to realize the indentation with the highest accuracy and stability is explained. Under these circumstances, regarding the theory, the following components are in the scope of this project:

$>$ force application with the highest accuracy

$>$ measurement cycle application precisely

$>$ indenter to realize the deformation

A certain amount of force is applied on a defined shape and material of indenter through a predefined application cycle comprising force application speed and time durations where the force is kept on the indenter applied and shown in figure 3.

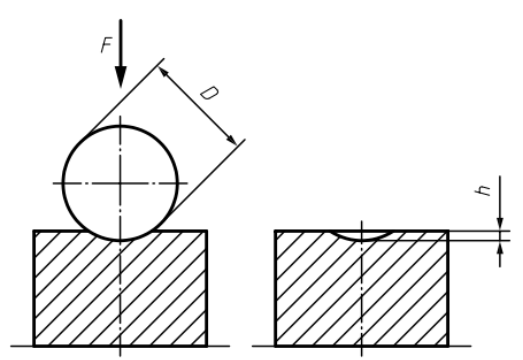

Figure 3: Realization of Brinell hardness indentation

After application of the measurement cycle, the realized indentation size, the diameter, is measured by some other device as shown in figure 4 . Then the measured diameter is used to calculate the Brinell Hardness by making use of eqn. 1 .

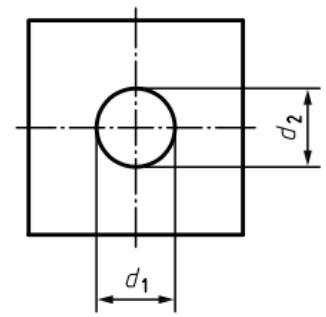

Figure 4: Measurement of Brinell hardness indentation

$$
\mathrm{HBW}=0,102 \times \frac{2 F}{\pi D^{2}\left(1-\sqrt{1-\frac{d^{2}}{D^{2}}}\right)}
$$

There are 21 Brinell Hardness Scales defined by the ISO Hardness Standard (ISO 6506-1:2014) [1] constituted with different combination of indenters and force values applied. The scales to be realized on this machine are highlighted in the table 1.

Table 1: Brinell Hardness Scales to be realized

\begin{tabular}{|l|c|c|c|}
\hline Hardness symbol & $\begin{array}{c}\text { Ball diameter } \\
D \\
m m\end{array}$ & $\begin{array}{c}\text { Force-diameter index } \\
0,102 \times F / D^{2}\end{array}$ & $\begin{array}{c}\text { Test force value } \\
F \\
\text { N }\end{array}$ \\
\hline HBW 10/3 000 & 10 & 30 & 29420 \\
\hline HBW 10/1500 & 10 & 15 & 14710 \\
\hline HBW 10/1 000 & 10 & 10 & 9807 \\
\hline HBW 10/500 & 10 & 5 & 4903 \\
\hline HBW 10/250 & 10 & 2,5 & 2452 \\
\hline HBW 10/100 & 10 & 1 & 980,7 \\
\hline HBW 5/750 & 5 & 30 & 7355 \\
\hline HBW 5/250 & 5 & 10 & 2452 \\
\hline HBW 5/125 & 5 & 5 & 1226 \\
\hline HBW 5/62,5 & 5 & 2,5 & 612,9 \\
\hline HBW 5/25 & 5 & 1 & 245,2 \\
\hline HBW 2,5/187,5 & 2,5 & 30 & 1839 \\
\hline HBW 2,5/62,5 & 2,5 & 10 & 612,9 \\
\hline HBW 2,5/31,25 & 2,5 & 5 & 306,5 \\
\hline HBW 2,5/15,625 & 2,5 & 2,5 & 153,2 \\
\hline HBW 2,5/6,25 & 2,5 & 1 & 61,29 \\
\hline HBW 1/30 & 1 & 30 & 294,2 \\
\hline HBW 1/10 & 1 & 10 & 98,07 \\
\hline HBW 1/5 & 1 & 5 & 49,03 \\
\hline HBW 1/2,5 & 1 & & \\
\hline HBW 1/1 & & 507 & \\
\hline
\end{tabular}




\section{DESIGN OF THE MACHINE}

The machine body was designed to be rigid and sturdy to minimize side effects during force application and realization of indentation, and every component constituting Brinell Hardness is considered to be with the highest accuracy to attain the best outcome quantity hardness.

\subsection{Body of the machine}

It is very important to have a rigid and strong enough body that will not affect the measurement results. For this reason, the machine body are designed to comprise the minimum number of parts and each having precise dimensional measurements and tight tolerances. See the CAD of the machine body in figure 5 .
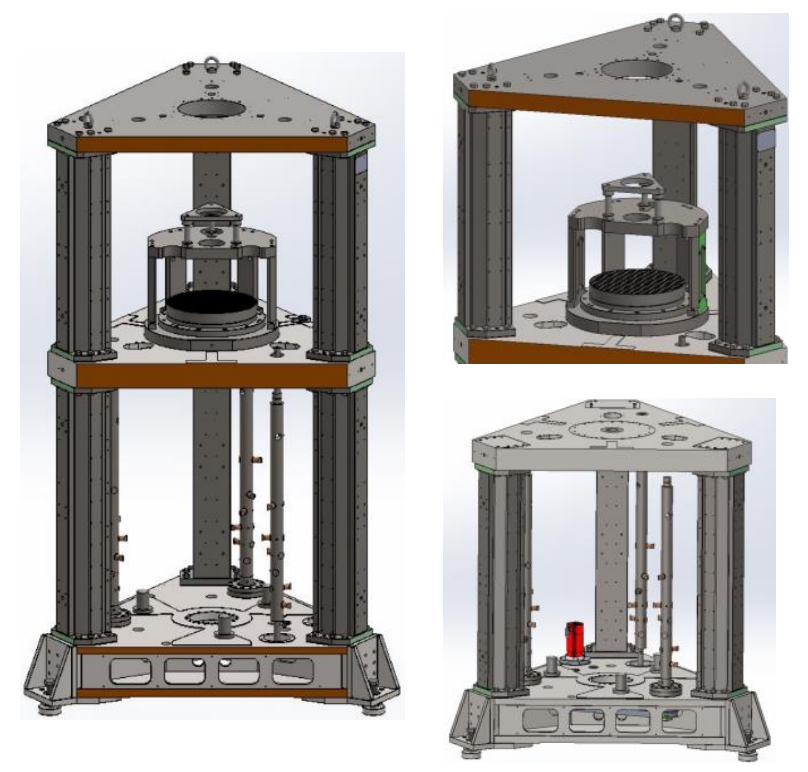

Figure 5: High Load Brinell Hardness Standard Machine

\subsection{Force Application System}

To realize the force with the highest accuracy and stability, deadweight type force application principle is preferred. It comprises mass stacks made up of stainless steel and a frame to constitute the first load and transfer the other loads to the tip of the indenter.

The frame is adjusted to apply $187.5 \mathrm{kgf}$ and the mass stacks will be in additional order to constitute the other force values and scales. The other mass stacks are $62.5 \mathrm{kgf}$ and $12 \times 250 \mathrm{kgf}$ to constitute the $250 \mathrm{kgf}, 500 \mathrm{kgf}, 750 \mathrm{kgf}, 1000 \mathrm{kgf}, 1500 \mathrm{kgf}$ and $3000 \mathrm{kgf}$ load steps including the frame itself. To prevent the frame from any pendulum and rotational motions during load application which will affect penetration performance of the indenter, it is guided by two air bearings at the two ends, both are working with (4-6) bar air pressure. The whole assembly of the masses and the frame are held by a high accurate force measurement sensor to control the testing cycle to measurement of the change in force in time and record the force application dwell time.
The masses are designed to occupy the smallest size for the smallest possible height and lateral sizes of the machine possibly locate it in Hardness Laboratory of TUBITAK UME. The masses are also planned to be with high accuracy since they will be used in recalibration of the force sensor equipped onto the machine and may be used for calibration or intermediate check of the force measurement devices used in calibration/verification hardness testing/calibration machines. The mass stacks are also guided while seating on each other and prevent any of the masses from possible rotation in time as loading and unloading is performed. To do so, some additional apparatus are mounted to the mass stacks at three points, like the corners of an equilateral triangle, and the masses are seated on top of each other. The 12 mass stacks and the frame constituting the high load Brinell scales are shown in figure 6.

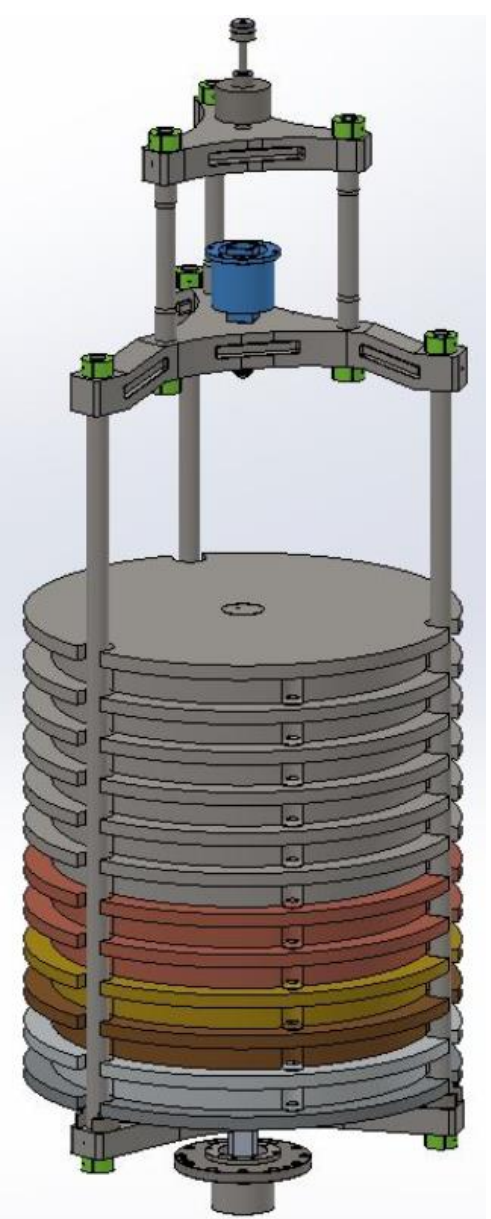

Figure 6: Force application system of High Load Brinell Hardness Standard Machine

\subsection{Measurement Cycle}

The measurement cycle is realized with application of force with a predefined indenter approach speeds and force application rates with respect to time. To figure out the measurement cycle of force application, a force measurement device is equipped onto the machine and data from this device is recorded. The force application time and duration of the force (load) application is measured by the change in force value of the force sensor 
with respect to the nominal (initial) load value. It is also possible to divide the force application speed (rate) into two different region for two different application rate. Any percent of the load to divide the regions and any force application rate for each region is possible. In this case it is avoided to make possible overshooting due to the possible final load application speed effect.

The approach speed of the indenter (or any other speed) is another parameter needs to be controlled. This is possible in two ways: The first a displacement measurement sensor can be equipped onto the machine and real time data can be collected and manipulated. The second way is to calibrate the motor speed by making use of the high accurate displacement measurement sensor and the speeds are set into the software without any direct measurement. Both option are available on this machine. The possible testing cycle of force application are given in figure 7 .

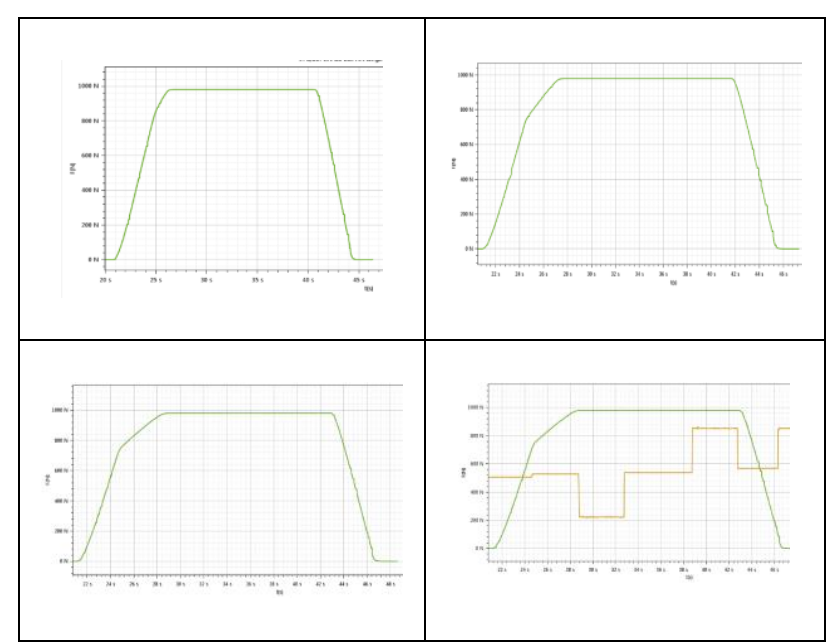

Figure 7: Brinell Hardness Indentation Realization Cycle

\subsection{Automation of the machine}

The machine is equipped with two servomotor, one force measurement sensor and optionally one displacement measurement sensor as the main component of the automation. The main servomotor (M1) is realizing the indentation by moving the force application system upand-down, the secondary servomotor (M2) is used to make the relevant mass stack to realize the relevant scale, load cell besides the measurement cycle is used to sense loading-unloading, parking etc.. There will be enough limit switches, ambient conditions measurement sensors and air pressure measurement gauge. It will be tried to perform closed loop control during load application to fix the load increase time in accordance with the load size and material properties like hardness.

\subsection{Performance of the machine}

In this paper the design of the machine is explained in detail, both in terms of mechanics and automation with hardware and software regarding the measurement cycle. The most important property of this machine is the accuracy and stability in force application method and the design of the system to realize precise and repeatable measurement cycle. As a full automatic dead weight force application system, after the implementation of this machine the force uncertainty is expected to be less than $5.10^{-5}$ relative, that value may go down to $2.10^{-5}$ relative. The time uncertainty in measurement cycle is expected to be less than $0.25 \mathrm{~s}$. The uncertainties of the force application will be assessed and the results will be published accordingly after installation of the machine in UME Hardness Laboratory.

\section{SUMMARY}

At the end of the work explained above;

- A deadweight type High Load Brinell Hardness Standard Machine is designed for first time at UME.

- It was designed to comprise the Brinell Hardness scale components with the highest accuracy to constitute the highest accurate indentation realization.

- The scale selection and the cycle of realization of indentation are all possible automatically.

\section{ACKNOWLEDGEMENTS}

The author would like to thank Mr. Çetin DOĞAN, Mr. Murat KARABINAOĞLU and Mr. Gökhan ÖNER from UME, the National Metrology Institute of Turkey, for their valuable contributions during the work has been done in this project of UME Hardness Laboratory.

\section{REFERENCES}

[1] EN ISO, 6506-1. Metallic Materials - Brinell Hardness Test - Part1: Test Method, 2014.

[2] EN ISO, 6506-3. Metallic Materials - Brinell Hardness Test - Part3: Calibration of Reference Blocks, 2014. 